\title{
Relationship between Invasive and Echocardiographic Transvalvular Gradients after Transcatheter Aortic Valve Replacement
}

\author{
Seyed Hossein Aalaei-Andabili (D) - Ki E. Park - Calvin Y. Choi • \\ Eddie W. Manning - Wade W. Stinson - Ryan Van Woerkom • \\ Thomas Pilgrim · Dharam J. Kumbhani · Anthony A. Bavry
}

Received: November 22, 2019 / Published online: January 22, 2020

(C) The Author(s) 2020

\begin{abstract}
Introduction: Lower transcatheter aortic valve replacement (TAVR) pressure gradients have been reported after implantation of self-expanding valves compared with balloon-expandable valves; however, there is a paucity of data on the relationship between invasively measured transvalvular pressure gradients and Doppler-derived measurements.
\end{abstract}

Enhanced digital features To view enhanced digital features for this article go to https://doi.org/10.6084/ m9.figshare.11494464.

S. H. Aalaei-Andabili · K. E. Park · C. Y. Choi · A. A. Bavry $(\square)$

Department of Medicine, University of Florida, Gainesville, FL, USA

e-mail: anthony.bavry@va.gov

K. E. Park · C. Y. Choi · E. W. Manning .

W. W. Stinson · A. A. Bavry

North Florida/South Georgia Veterans Health

System, Gainesville, FL, USA

E. W. Manning · W. W. Stinson

Department of Surgery, University of Florida,

Gainesville, FL, USA

R. Van Woerkom · D. J. Kumbhani

Department of Medicine, University of Texas

Southwestern, Dallas, TX, USA

T. Pilgrim

Department of Cardiology, University of Bern, Bern,

Switzerland
Methods: From September 2013 to September 2018, patients with native aortic valve stenosis who had both intraoperative invasive and postoperative echocardiography transvalvular pressure gradients were included for analysis. We used parametric and nonparametric statistics to compare aortic gradients within and between groups.

Results: Of 171 patients, 152 (88.9\%) patients had TAVR with a balloon-expandable valve and $19(11.1 \%)$ with a self-expanding valve. Among all patients, the invasive aortic gradient was $7.8 \pm 3.2 \mathrm{mmHg}$ and the Doppler-derived aortic gradient was $11.0 \pm 4.5 \mathrm{mmHg} \quad(p<0.001)$. Among those who received a balloon-expandable valve, the invasive aortic gradient was $7.5 \pm 3 \mathrm{mmHg}$ and the Doppler aortic gradient was $11.4 \pm 4.5 \mathrm{mmHg}(p<0.001)$. In contrast, among patients who received a self-expanding valve, the invasive aortic gradient was $10.3 \pm 3.4 \mathrm{mmHg}$ and the Doppler aortic gradient was $8.5 \pm 4.6 \mathrm{mmHg}(p=0.18)$.

Conclusions: Balloon-expandable valves were associated with lower invasive measurements versus post-TAVR Doppler gradients, while results were inconclusive regarding self-expanding valves.

Keywords: Balloon-expanding valve; Doppler aortic gradient; Invasive aortic gradient; Selfexpanding valve; TAVR 


\section{INTRODUCTION}

Transcatheter aortic valve replacement (TAVR) is approved for use in patients with symptomatic severe aortic stenosis irrespective of risk [1-3]. Therefore, prosthetic TAVR valve competency and durability are crucial. Post-procedural transvalvular pressure gradients have been found to be associated with biomechanical stress and deterioration of the prosthetic valve [4]. Previous studies have shown higher postoperative Doppler aortic gradients in balloonexpandable valves versus self-expanding valves [5]; however, there is a paucity of data regarding the correlation of aortic valve gradients obtained invasively and from Doppler-derived measurements. Our aim was to compare invasive versus post-operative Doppler-derived transvalvular pressure gradients after TAVR.

\section{METHODS}

The University of Florida Institutional Review Board approved this retrospective study. The study was performed in accordance with the Declaration of Helsinki of 1964 and its later amendments. Informed consent was obtained from all patients for the TAVR procedure. From September 6, 2013, to September 1, 2018, 284 patients with symptomatic severe aortic valve stenosis underwent TAVR at the Malcom Randall Veterans Medical Center in Gainesville, Florida. Among them, 182 patients had both intraoperative invasively measured and postoperative Doppler-derived transvalvular pressure gradient measurements. Eleven patients with valve-in-valve TAVR were excluded; therefore, 171 patients with native aortic valve stenosis were included for final analysis. All TAVR procedures were performed according to current guidelines and standard approaches $[6,7]$. Intraoperative invasive transvalvular mean pressure gradient was measured using a Langston dual-lumen pigtail catheter 5-10 min after valve deployment. Postoperative Dopplerderived transvalvular mean pressure gradient was assessed with transthoracic echocardiography within $48 \mathrm{~h}$ after TAVR after bedrest restrictions had been lifted. Invasively measured transvalvular pressure gradients and post-operative Doppler-derived measurements were compared among all patients and according to valve type. Student's $t$ test was used for comparison of parametric variables (balloon-expandable valves) and the Wilcoxon rank-sum test was employed for comparison of nonparametric variables (self-expanding valves). To examine the correlation between invasively measured and postoperative Doppler-derived transvalvular measurements, we used Pearson's correlation test. A two-tailed $p$ value $\leq 0.05$ was considered statistically significant. Statistics were performed with SPSS software (Version 24, IBM Co., Armonk, NY, USA).

\section{RESULTS}

From 171 patients with native aortic valve stenosis who had both invasively measured and postoperative Doppler-derived transvalvular pressure gradient measurements, 152 (88.9\%) received a balloon-expandable valve and 19 (11.1\%) a self-expanding valve. Mean \pm SD age was $76.9 \pm 9.1$ years, and the majority of patients were men $(n=167,97.7 \%)$. The mean \pm SD pre-procedure mean aortic gradient was $41.5 \pm 12.4 \mathrm{mmHg}$. The overall mean $\pm \mathrm{SD}$ invasive mean aortic gradient was $7.8 \pm 3.2 \mathrm{mmHg}$, and the Doppler-derived

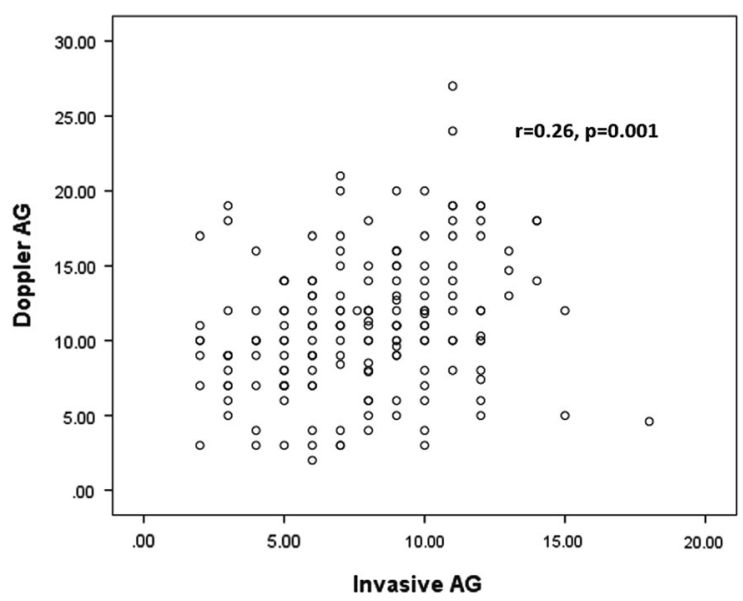

Fig. 1 Correlation between intraoperative invasive and post-operative Doppler aortic gradients (AG) 
mean aortic gradient was $11.0 \pm 4.5 \mathrm{mmHg}$ $(p<0.001)$ (Fig. 1).

Mean area-derived and perimeter-derived diameters were comparable between balloonexpandable and self-expanding valves (Table 1). Among patients who underwent TAVR with a balloon-expandable valve, the invasive mean aortic gradient was $7.5 \pm 3 \mathrm{mmHg}$ and the Doppler-derived mean aortic gradient was $11.4 \pm 4.5 \mathrm{mmHg}(p<0.001)$. In contrast, in patients who received a self-expanding valve, the invasive mean aortic gradient was $10.3 \pm 3.4 \mathrm{mmHg}$ and Doppler-derived mean aortic gradient was $8.5 \pm 4.6 \mathrm{mmHg}(p=0.18)$.

One hundred and forty-six patients had TAVR with a new-generation Sapien 3 valve. The invasive mean aortic gradient was $7.4 \pm 3 \mathrm{mmHg}$, and the Doppler-derived mean aortic gradient was $11.5 \pm 4.5 \mathrm{mmHg}$ and $(p<0.001)$. Among 14 patients who underwent
TAVR with an Evolut R or Evolut Pro valve, the invasive mean aortic gradient was $10.1 \pm 3.7 \mathrm{mmHg}$, and the Doppler-derived mean aortic gradient was $7.7 \pm 4.5 \mathrm{mmHg}$ $(p=0.14)$.

\section{DISCUSSION}

This study reports on bioprosthetic TAVR valve hemodynamics. We document the following findings: (1) Balloon-expandable valves were associated with lower invasively measured transvalvular pressure gradients versus postTAVR Doppler-derived gradients. (2) Among self-expanding valves, invasive gradients were similar versus post-TAVR Doppler-derived gradients.

Now that the United States Food and Drug Administration has approved TAVR for low

Table 1 Annulus diameter, invasive and Doppler aortic gradients according to valve type

\begin{tabular}{|c|c|c|c|c|c|c|c|}
\hline Valve & Number & $\begin{array}{l}\text { Valve size } \\
\text { mm }(n)\end{array}$ & $\begin{array}{l}\text { Area-derived } \\
\text { diameter }\end{array}$ & $\begin{array}{l}\text { Perimeter- } \\
\text { derived } \\
\text { diameter }\end{array}$ & $\begin{array}{l}\text { Invasive } \\
\text { mean } \\
\text { gradient }\end{array}$ & $\begin{array}{l}\text { Echo mean } \\
\text { gradient }\end{array}$ & $p$ value \\
\hline Total & 171 & & $25.2 \pm 1.8$ & $25.7 \pm 1.9$ & $7.8 \pm 3.2$ & $11.0 \pm 4.5$ & $<0.001$ \\
\hline \multirow[t]{3}{*}{ Balloon-expandable } & 152 & $23(14)$ & $25.3 \pm 1.9$ & $25.8 \pm 1.9$ & $7.5 \pm 3$ & $11.4 \pm 4.5$ & $<0.001$ \\
\hline & & $26(82)$ & & & & & \\
\hline & & $29(56)$ & & & & & \\
\hline \multirow[t]{3}{*}{ Sapien 3} & 146 & $23(14)$ & $25.3 \pm 1.9$ & $25.8 \pm 1.9$ & $7.4 \pm 3$ & $11.5 \pm 4.5$ & $<0.001$ \\
\hline & & $26(78)$ & & & & & \\
\hline & & $29(54)$ & & & & & \\
\hline \multirow[t]{4}{*}{ Self-expanding } & 19 & $26(1)$ & $24.8 \pm 1.8$ & $25.5 \pm 1.8$ & $10.3 \pm 3.4$ & $8.5 \pm 4.6$ & 0.18 \\
\hline & & $29(10)$ & & & & & \\
\hline & & $31(4)$ & & & & & \\
\hline & & $34(4)$ & & & & & \\
\hline \multirow[t]{3}{*}{ Evolut R/Pro } & 14 & $26(1)$ & $24.4 \pm 1.8$ & $25.1 \pm 1.9$ & $10.1 \pm 3.7$ & $7.7 \pm 4.5$ & 0.14 \\
\hline & & $29(9)$ & & & & & \\
\hline & & $34(4)$ & & & & & \\
\hline $\begin{array}{l}p \text { value for balloon vs. } \\
\text { self-expanding }\end{array}$ & & & 0.25 & 0.47 & 0.002 & 0.016 & \\
\hline
\end{tabular}


surgical risk patients with potentially younger age, bioprosthetic valve durability and proper function are vital for freedom from symptoms and reoperation. Post-TAVR transvalvular pressure gradients and valve hemodynamics have important roles in valve durability and patient outcomes [8]. Higher aortic gradients after implantation are associated with more biomechanical stress and valve deterioration [9].

The finding that self-expanding valves were associated with lower Doppler-derived aortic valve gradients than balloon-expandable valves confirms previous studies $[5,10,11]$. Lower transvalvular gradients in self-expanding versus balloon-expandable valves after TAVR may be related to supra-annular function of the selfexpanding valves [12]. Regarding invasive measurements, there was a suggestion that balloon-expandable valves were associated with lower trans-valvular gradients than self-expanding valves; however, due to limited numbers, this needs to be interpreted with extreme caution.

Overestimation of transvalvular gradients from Doppler-derived measurements versus invasive measurements is well described to occur in native aortic stenosis and after TAVR and is attributed to the pressure recovery phenomenon [13-17]. A schematic diagram of pressure recovery between invasive and Doppler-derived measurements is illustrated in Fig. 2 [18]. Invasive measurements are able to account for pressure recovery by measuring the aortic pressure at the point where turbulent flow converges to laminar flow. It is possible that invasive pressure acquisition might be

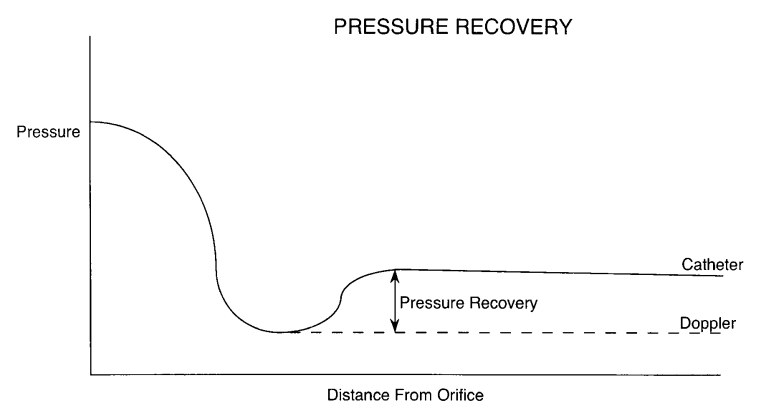

Fig. 2 Schematic diagram of pressure recovery between invasive and echocardiography techniques. Reprinted with permission from [18] different between valve types. For example, when a dual-lumen pigtail catheter is used within a self-expanding valve, the aortic pressure might be measured within a region of turbulent flow and thus not able to fully account for pressure recovery and overestimate the transvalvular pressure gradient. Accordingly, use of two single-lumen pigtail catheters might be preferential for assessment of self-expanding valve hemodynamics. This could also help to explain the possible difference in invasive pressures between valve types.

Other study limitations include: (1) This was a single-center retrospective study with limited sample size, especially for self-expanding valves, which precluded direct comparison between valve types. (2) High-fidelity micromanometer catheter tips (i.e., Millar) were not used; however, our technique for obtaining pressures was meticulous and systematic. (3) Increases in stroke volume, which are known to increase Doppler gradients, were not directly accounted for (i.e., post-procedural anemia) and were assumed to be similar. This was a potential issue since transthoracic echocardiography was performed within $48 \mathrm{~h}$ after TAVR.

\section{CONCLUSIONS}

Balloon-expandable valves were associated with lower invasive gradients versus post-TAVR Doppler-derived gradients. Further studies with larger patient populations are warranted to better understand bioprosthetic TAVR valves hemodynamics.

\section{ACKNOWLEDGEMENTS}

Funding. No funding or sponsorship was received for this study or publication of this article.

Authorship. All named authors meet the International Committee of Medical Journal Editors (ICMJE) criteria for authorship for this article, take responsibility for the integrity of 
the work as a whole, and have given their approval for this version to be published.

Disclosures. Seyed Hossein Aalaei-Andabili, Ki Park, Calvin Choi, Eddie Manning, Wade Stinson, Ryan Van Woerkom, Thomas Pilgrim, and Dharam Kumbhani have nothing to disclose. Anthony A. Bavry has received honoraria from the American College of Cardiology and Edwards Lifesciences. Anthony A. Bavry is a member of the journal's Editorial Board.

Compliance with Ethics Guidelines. The University of Florida Institutional Review Board approved this retrospective study. The study was performed in accordance with the Declaration of Helsinki of 1964 and its later amendments. Informed consent was obtained from all patients for being included in the study.

Data Availability. The datasets generated during and/or analyzed during the current study are available, in anonymized form to protect patient privacy, from the corresponding author on reasonable request.

Open Access. This article is distributed under the terms of the Creative Commons Attribution-NonCommercial 4.0 International License (http://creativecommons.org/licenses/ by-nc/4.0/), which permits any non-commercial use, distribution, and reproduction in any medium, provided you give appropriate credit to the original author(s) and the source, provide a link to the Creative Commons license, and indicate if changes were made.

\section{REFERENCES}

1. Leon MB, Smith CR, Mack MJ, et al. Transcatheter or surgical aortic-valve replacement in intermediate-risk patients. $\mathrm{N}$ Engl J Med. 2016;374(17): 1609-20.

2. Mack MJ, Leon MB, Thourani VH, et al. Transcatheter aortic-valve replacement with a balloonexpandable valve in low-risk patients. N Engl J Med. 2019;380(18):1695-705.
3. Popma JJ, Deeb GM, Yakubov SJ, et al. Transcatheter aortic-valve replacement with a self-expanding valve in low-risk patients. $\mathrm{N}$ Engl J Med. 2019;380(18):1706-15.

4. Johnston DR, Soltesz EG, Vakil N, et al. Long-term durability of bioprosthetic aortic valves: implications from 12,569 implants. Ann Thorac Surg. 2015;99(4):1239-47.

5. Abdel-Wahab M, Mehilli J, Frerker C, et al. Comparison of balloon-expandable vs self-expandable valves in patients undergoing transcatheter aortic valve replacement: the CHOICE randomized clinical trial. JAMA. 2014;311(15):1503-14.

6. Otto CM, Kumbhani DJ, Alexander KP, et al. 2017 ACC Expert Consensus Decision Pathway for Transcatheter Aortic Valve Replacement in the Management of Adults With Aortic Stenosis: a Report of the American College of Cardiology Task Force on Clinical Expert Consensus Documents. J Am Coll Cardiol. 2017;69(10):1313-46.

7. Mitchell C, Rahko PS, Blauwet LA, et al. Guidelines for performing a comprehensive transthoracic echocardiographic examination in adults: recommendations from the American Society of Echocardiography. J Am Soc Echocardiogr. 2019;32(1):1-64.

8. Bavry AA, Karimi A, Park KE, et al. Aortoventricular index predicts long-term mortality after transcatheter aortic valve replacement. JACC Cardiovasc Interv. 2019;12(22):2327-9.

9. Sondergaard L, Ihlemann N, Capodanno D, et al. Durability of transcatheter and surgical bioprosthetic aortic valves in patients at lower surgical risk. J Am Coll Cardiol. 2019;73(5):546-53.

10. Abdelghani M, Mankerious N, Allali A, et al. Bioprosthetic valve performance after transcatheter aortic valve replacement with self-expanding versus balloon-expandable valves in large versus small aortic valve annuli: insights from the CHOICE Trial and the CHOICE-Extend Registry. JACC Cardiovasc Interv. 2018;11(24):2507-18.

11. Ochiai T, Yoon SH, Sharma R, et al. Outcomes of self-expanding vs. balloon-expandable transcatheter heart valves for the treatment of degenerated aortic surgical bioprostheses-a propensity score-matched comparison. Circ J. 2018;82(10): 2655-62.

12. Azadani AN, Reardon M, Simonato M, et al. Effect of transcatheter aortic valve size and position on valve-in-valve hemodynamics: an in vitro study. J Thorac Cardiovasc Surg. 2017;153(6):1303-15 e1. 
13. Baumgartner $H$, Stefenelli $T$, Niederberger J, Schima H, Maurer G. "Overestimation" of catheter gradients by Doppler ultrasound in patients with aortic stenosis: a predictable manifestation of pressure recovery. J Am Coll Cardiol. 1999;33(6):1655-61.

14. Firstenberg MS, Abel EE, Papadimos TJ, Tripathi RS. Nonconvective forces: a critical and often ignored component in the echocardiographic assessment of transvalvular pressure gradients. Cardiol Res Pract. 2012;2012:383217.

15. Abbas AE, Mando R, Hanzel G, et al. Invasive versus echocardiographic evaluation of transvalvular gradients immediately post-transcatheter aortic valve replacement. Circ Cardiovasc Interv. 2019;12(7): e007973.
16. Levine RA, Jimoh A, Cape EG, McMillan S, Yoganathan AP, Weyman AE. Pressure recovery distal to a stenosis: potential cause of gradient "overestimation" by Doppler echocardiography. J Am Coll Cardiol. 1989;13(3):706-15.

17. Yoganathan AP, Valdes-Cruz LM, Schmidt-Dohna J, et al. Continuous-wave Doppler velocities and gradients across fixed tunnel obstructions: studies in vitro and in vivo. Circulation. 1987;76(3): 657-66.

18. Cape EG, Jones M, Yamada I, VanAuker MD, Valdes-Cruz LM. Turbulent/viscous interactions control Doppler/catheter pressure discrepancies in aortic stenosis. The role of the Reynolds number. Circulation. 1996;94(11):2975-81. 